TẠP CHÍ KHOA HỌC ĐẠI HỌC TÂN TRÀO

ISSN: 2354 - 1431

http://tckh.daihoctantrao.edu.vn/

\title{
ĐÓNG GÓP CỦA THÁI PHÓ HÀ DI KHÁNH ĐỐI VỚI LỊCH SỬ DÂN TỘC THẾ KỶ XI - XII
}

\author{
Hoàng Thị Thu Dung, Trần Minh Tú $a^{*}$ \\ ${ }^{a}$ Trưòng Đại học Tân Trào \\ *Email: hoangthithudung@gmail.com
}

\section{Thông tin bài viết}

Ngày nhận bài:

26/2/2020

Ngày duyệt đăng:

10/6/62020

Tù khóa:

Đóng góp, Hà Di Khánh, lịch sử dân tộc

\section{Tóm tắt}

Hiện nay, tại chùa Bảo Ninh Sùng Phúc (huyện Chiêm Hóa, Tuyên Quang) còn lưu giữ được tấm bia cổ duy nhất thuộc các tỉnh miền núi phía Bắc nước ta có niên đại từ thời nhà Lý. Nội dung văn bia chép về dòng họ Hà và những đóng góp của dòng họ này đối với vùng đất $\mathrm{Vị} \mathrm{Long} \mathrm{nói} \mathrm{riêng} \mathrm{và} \mathrm{đất} \mathrm{nước} \mathrm{nói}$ chung ở thế kỷ XI - XII. Trong đó phải kể đến công lao to lớn của nhân vật lịch sử Hà Di Khánh.

\section{Mở đầu}

Vào thế kỷ X - XI, Châu Vị Long có vị trí địa lý, chính trị đặc biệt quan trọng của quốc gia Đại Việt. Châu Vị Long cơ bản là vùng đất thuộc tỉnh Tuyên Quang ngày nay. Châu Vị Long bao gồm ít nhất địa bàn của ba huyện: Chiêm Hóa, Na Hang và Hàm Yên, vị trí trung tâm của châu là Chiêm Hóa, tỉnh Tuyên Quang. Đó là vùng đất có điều kiện tự nhiên thuận lợi, đất đai tương đối màu mỡ, giàu tài nguyên khoáng sản. Các dân tộc Chiêm Hoá mặc dù có nguồn gốc lịch sử khác nhau nhưng họ cùng nhau sinh sống, tích cực khai phá, mở mang ruộng đồng, xây làng lập bản để làm nơi sinh cơ lập nghiệp và phát triển lâu dài.

Là vùng đất rộng người thưa, núi non hiểm trở, có vị trí chiến lược về quốc phòng, đồng bào các dân tộc nơi đây có truyền thống đoàn kết, yêu nước, giàu lòng nhân ái, dũng cảm trong đấu tranh chống cường quyền, áp bức, đánh giặc ngoại xâm; cần cù, sáng tạo trong lao động và có đời sống văn hoá tinh thần khá phong phú, độc đáo.

\footnotetext{
${ }^{1}$ Tại cuộc hội thảo khoa học về cỏc danh nhõn họ Hà chõu Vị Long Tuyờn Quang và giỏ trị tấm bia Bảo Ninh Sựng Phỳc tự bi đó kết luận, nhõn vật Hà Di Khỏnh được khắc trong văn bia Bảo Ninh Sựng Phỳc và Hà Hưng Tụng được ghi trong cuốn Đại Việt sử ký toàn thư là một. ${ }^{2}$ Bảo Ninh Sựng Phỳc tự bi là 1 trong số 18 tấm bia cổ cú giỏ trị được khắc dưới thời nhà Lý hiện cũn được lưu giữ. Bia cú niờn đại vào loại sớm và cú giỏ trị về nhiều mặt (Lị ch sử, Văn húa). Nếu tớnh riờng cỏc
}

Hiện nay, tại thôn làng Tạc, xã Yên Nguyên, huyện Chiêm Hóa, tỉnh Tuyên Quang còn lưu giữ tấm bia cổ Bảo Ninh Sùng Phúc tụ bi và nhiều dấu tích khảo cổ học có niên đại nhà Lý (1009 - 1225) minh chứng cho một thời kỳ lịch sử đáng tự hào của vùng đất này. Địa danh chùa cổ Bảo Ninh Sùng Phúc, tấm bia cổ Bảo Ninh Sùng Phúc tự bi đã gắn liền với nhân vật lịch sử - danh nhân Hà Di Khánh, với những đóng góp to lớn của ông cho lịch sử dân tộc thế kỷ XI - XII.

\section{Nội dung nghiên cứu}

\subsection{Thân thế và sự nghiệp của Hà Di Khánh}

Thái phó Hà Di Khánh ${ }^{1}$ là nhân vật lịch sử sống và hoạt động vào nửa cuối thế kỷ XI, đầu thế kỷ XII tại châu Vị Long, nơi có vị trí địa lý, chính trị đặc biệt quan trọng của quốc gia Đại Việt. Châu Vị Long cơ bản là vùng đất thuộc huyện Chiêm Hóa, tỉnh Tuyên Quang ngày nay.

Tại xã Yên Nguyên, Chiêm Hoá, Tuyên Quang hiện còn lưu giữ được tấm bia cổ Bảo Ninh Sùng Phúc ${ }^{2}$ của tác giả Lý Thừa $\hat{A}^{3}$ soạn vào năm 1107 , do chính Thái phó Hà Di Khánh lệnh viết. Tấm bia cổ phần nào đã

tỉ nh thượng du phớa Bắc thỡ Bảo Ninh Sựng Phỳc tự bi hiện đang lưu giữ tại Chiờm Húa, Tuyờn Quang là tấm bia đỏ được khắc duy nhất dưới thời nhà Lý.

${ }^{3} \boldsymbol{L} \boldsymbol{y}$ Thừa $\hat{A} \boldsymbol{n}$ là quan văn dưới thời nhà Lý, khụng rừ năm sinh, năm mất. Đương thời, ụng làm đến Triều thỉ nh đại phu, thượng thư, viờn ngoại lang, năm Nhõm Tý 1132, đời Lý Thần Tụng, ụng cú đi sứ nhà Tống. 
cho chúng ta những thông tin chân thực và quý báu về tiểu sử và gia thế của Thái phó Hà Di Khánh.

Bia cổ Bảo Ninh Sùng Phúc ghi chép khá rõ về quê hương của Thái phó Hà Di Khánh: “Thái phó Hà Hung Tông, Thuỷ tổ người thôn Ca Nông, huoong Thạch Bách, huyện Hà, thuộc Đông Đô, Châu Ung . Cao tổ là Hà Đắc Trọng, xa nghe giáo hoá của vuoong triều, dời gót xin làm thần thứ, tù đó giũ gìn an toàn châu Vị Long vậy. Dân đã ấm no; người đời tôn tường. Cho tới đời thứ 8 , kể cả tổ tiên xua có hai đời làm Thái bảo và Thái phó, nghiệp lớn càng thịnh; công cả càng cao. Được coi giư 49 động, 15 huyện, dân khuân phép chung. Trải qua 5 đời thì đến đời bấy giò̀. Ông của Thái phó (Hà Di Khánh) giũ chưc Thái bảo, lấy công chúa thứ 3 của của Thái Tổ Hoàng đế (Tức Lý Thái Tổ - 1009-1028)" [5, Tr114].

Như vậy, quê gốc của Thái phó Hà Di Khánh là châu Ung, thuộc Nam Ninh, tỉnh Quảng Tây, Trung Quốc ngày nay. Theo văn bia thì từ vị cao tổ Hà Đắc Trọng đến thời Hà Di Khánh (cụ thể dựng bia năm 1107) là 8 đời. Như vậy, Họ Hà định cư tại Châu Vị Long đến đời Hà Di Khánh là khoảng 200 năm. Từ đó có thể thấy được rằng, thủy tổ của họ Hà di cư vào châu Vị Long vào đầu thế kỷ thứ X, tức khoảng năm 905 đến năm 920 . Đó là thời kỳ loạn lạc ở Trung Quốc ${ }^{5}$. Vùng châu Ung, quê hương của họ Hà cũng không phải là ngoại lệ. “chắc hẳn là Hà Đắc Trọng đã di cu sang châu Vị Long vào khoảng thời gian này để tránh họa giặc giã tại cố huoong” [6, Tr16].

Họ Hà từ châu Ung (Trung Quốc) di cư sang Vị Long. Đến đời ông của Thái phó Hà Di Khánh được giữ chức Thái bảo ${ }^{6}$, lấy công chúa thứ ba của Thái Tổ Hoàng đế Lý Công Uẩn làm phu nhân. Nhân việc đó được vua Lý Thái Tổ giao giữ chức Hũu đại liêu ban ${ }^{\mathbb{1}}$. Ông Bà nội của Thái phó sinh được bẩy người con, bốn con trai và ba con gái.

Thân phụ của Thái phó là người chính trực, đại nghĩa, lấy đức trị dân. Theo văn bia viết “...Riêng thân phu Thái phó là người thi hành nhân chính, làng xóm yên vui..."

${ }^{4}$ Chõu Ung: Nay thuộc tỉ nh Quảng Tõy, trung Quốc.

${ }^{5}$ Thời kỳ Ngũ đại Thập quốc là thời kỳ hết sức loạn lạc ở Trung Quốc, giặc dó nổi lờn khắp nơi.

${ }_{6}^{6}$ Thỏi bảo: Quan Nhất phẩm trong hàng ngũ vú quan của triều đỡnh nhà Lý.

${ }^{1}$ Hũu đại liờu ban: Theo quan chế triều Lý, đõy là một tước phong cho cóc cung thần của triều đỡnh.

${ }^{2}$ Tuổi mụ: Theo cỏch tớnh cổ truyền, tuổi cú ngay từ lỳc mới sinh ra, tớnh năm sinh đó là 1 tuổi.

${ }^{3}$ Tả Đại liờu ban: Là một chức phong. Theo Lờ Quý Đụn trong Kiến văn tiểu lục nhũng người được phong tước trờn đều là những cụng thần.
[5, tr. 114]. Thân phụ Thái phó kết duyên với con gái thứ 6 của quan Thái thú ở Phú Nghĩa và “tù khi sinh người con trai đầu lòng đến người con trai thứ tux, cha mẹ Thái phó đều nuôi dậy ân cần... Con trai thì rùi mài kinh sủ, con gái thì kim chỉ thêu thùa" [5, tr114].

Về năm sinh của Thái phó Hà Di Khánh, chính sử không thấy chép, nhưng văn bia Bảo Ninh Sùng Phúc cho biết “ Vu Anh Vũ Chiêu Thắng, Đinh Ty, thời duy cửu tuế, tử nê phong chiếu..." - Dịch "Năm Đinh Ty, niên hiệu Anh Vũ Chiêu Thắng (1077) lúc bấy giò, ông (tức Thái phó Hà Di Khánh - TG) mới chỉ có 9 tuổi” [5, Tr115]. Ngày xưa, tính tuổi, người ta thường hay tính cả tuổi mụ ${ }^{2}$. Như vậy, nếu tính theo tuổi Dương lịch (tuổi Tây), vào năm 1077, Hà Di Khánh mới chỉ có 8 tuổi, từ đó suy ra, ông sinh vào năm Kỷ Dậu (1069).

Năm 1082, vua Lý gả công chúa Khâm Thánh cho Hà Di Khánh và phong cho ông chức Tả Đại liêu $b a n^{3}$.

Năm Ất Sửu (1085), thân phụ Hà Di Khánh qua đời, năm Bính Dần (1086), ông được thế tập cha giữ chức tri châu Vị Long. Giữ Tiết độ sứ 4 , Kim tử Quang lộc đại phu, Kiểm hiệu Thái phó ${ }^{5}$, Châu mục ${ }^{6}$ châu Vị Long Tức người cai quản toàn bộ công việc quân, dân, chính của châu $\mathrm{Vị} \mathrm{Long} \mathrm{và} \mathrm{phòng} \mathrm{giữ} \mathrm{vững} \mathrm{chắc} \mathrm{vùng} \mathrm{biên} \mathrm{giới}$ phía Bắc của Tổ quốc.

Theo văn bia Bảo Ninh Sùng Phúc, thì tri châu Vị Long là Hà Di Khánh coi giữ 49 động, 15 huyện, dân chúng đều ấm no, thấm nhuần giáo lý tốt đẹp, hướng theo khuôn phép chung. Chúng ta đều biết Động là đơn vị hành chính ở vùng miền núi, thượng du vào thời bấy giờ, tương đương với đơn vị Huoong ở đồng bằng, còn đơn vị hành chính Huyện ở vùng thượng du có lẽ nhỏ hơn đơn vị Huyện ở vùng đồng bằng, miền xuôi và nằm trong đơn vị hành chính Châu (trực thuộc Châu) thời bấy giờ.

${ }^{4}$ Tiết độ sứ: Là chức quan cao cấp đứng đầu việc quân và chính quyền của địa phương.

Theo văn bia, chức Tiết độ sứ mà Thái phó Hà Di Khánh nắm giữ được nhà Lý giao cho toàn quyền xử trí các công việc địa phương do mình quản giữ.

${ }^{5}$ Kiểm hiệu Thỏi phú: Là một chức quan được phong trong thời gian chờ đợi được chớnh thúc thụ phong.

${ }^{6}$ Chõu mục: cũng tức là Tri chõu. 
Theo PSG. TS Nguyễn Minh Tường7 "Châu Vị Long gồm 49 động và 15 huyện nhu văn bia ghi chép chắc hẳn phải rộng hơn huyện Chiêm Hóa, tỉnh Tuyên Quang ngày nay khá nhiều" PGS cũng cho rằng: "Phạm vi châu Vị Long do Tri châu Hà Di Khánh Quản lý có thể bao gồm 3 huyện Chiêm Hóa, Na Hàng, Yên Sơn, một phần huyện Hàm Yên và Sơn Dưong, tỉnh Tuyên Quang ngày nay. Chỉ đứng đầu một vùng đất rộng nhu vậy thì Thái phó Hà Di Khánh mói được vua Lý Nhân Tông coi trọng và gả công chúa Khâm Thánh, em gái vua, phong làm Phò Mã "[6, tr13].

\section{2. Đóng góp của Hà Di Khánh đối với lịch sử dân tộc thế kỷ XI - XII}

Công lao đầu tiên và lớn nhất của Thái phó Hà Di Khánh đối với lịch sử dân tộc và với vùng đất Vị Long (Chiêm Hóa, Tuyên Quang) là giữ vững và góp phần ổn định vùng biên cương phía Bắc của Tổ quốc.

Vào thời Lý, vùng biên cương phía Bắc nước ta là một vùng đất rộng, dài, suốt dải biên giới dài hơn 1000 km ấy chỉ có đoạn Cao Bằng sang phía Đông là khá rõ ràng, còn về phía Tây thì chưa thật ổn định.

Nhận thức được tầm quan trọng của vùng đất biên viễn, khối đoàn kết dân tộc, trong lịch sử, các triều đại phong kiến Việt Nam luôn có những chính sách dân tộc đối với các vùng, các dân tộc khác nhau, nhằm duy trì và khẳng định quyền lực của nhà Vua đối với các dân tộc thiểu số. Hướng tới mục đích củng cố và tăng cường nền thống nhất quốc gia.

Năm Ất Mão đời Thái Ninh (1075), Trong cuộc kháng chiến chống quân xâm lược Tống của Lý Thường Kiệt, phụ thân của Hà Di Khánh đã cầm quân sang đánh thành Ung Châu và lập công lớn, bắt được tướng giặc và tù binh. Trong chiến dịch Tiên phát chế nhân, nhà Lý đã huy động quân đội các dân tộc thiểu số sang đánh bằng đường bộ. Trong khi đại quân của triều đình do Lý Thường Kiệt chỉ huy đi thuyền, đổ bộ lên Liêm Châu, tiến đánh mặt sau Ung Châu. Ngày 27-10-1075 cuộc tiến công bắt đầu. Đạo quân của châu Vị Long cùng với quân đội của các vùng khác do các thủ lĩnh các dân tộc thiểu số chỉ huy chia thành nhiều mũi, phối hợp với quân đội triều đình bất ngờ tiến công vào toàn bộ đồn, trại của quân Tống dọc biên giới. Trước sự tấn công bất ngờ, táo bạo của quân ta, quân Tống không sao chống đỡ nổi, hàng ngũ rối loạn, số thì bị giết,

${ }^{7}$ PGS. TS Nguyễn Minh Tường hiện cụng tỏc tại Viện Sử học Việt Nam

${ }^{8}$ Đường biờn giới hiện nay giữa Việt Nam và Trung Quốc cú tổng chiều dài là $1.449 .566 \mathrm{~km}$, trong đú đường biờn giới trờn bộ là $1.065 .652 \mathrm{~km}$, số còn lại vội vã bỏ đồn trại tháo chạy về phía Ung Châu. Âm mưu tiến đánh Đại Việt của nhà Tống bị phá sản.

Trong bia Bảo Ninh Sùng Phúc cũng viết rõ "Năm Ât Mão, niên hiệu Thái Bình (1075), Thân phu Thái phó chỉnh đốn vuơng sụ, đánh sang ải Bắc. Vây thành Ung cho bỏ giận; bắt tuoóng võ, dâng tù binh. Do đó thân phu Thái phó được vua ban chức Hũu đại liêu ban đoàn luyện sú" [6, tr73-74].

Với chiến công ấy, phụ thân ông được giữ chức Hũu đại liêu ban, Đoàn luyện sứ. Có thể thấy, trong cuộc kháng chiến chống Tống, bên cạnh sự đóng góp của họ Thân, họ Vi ở Lạng Châu thì họ Hà ở Vị Long - Chiêm Hóa Tuyên Quang đã tích cực đóng góp công sức cho cuộc chiến.

Công lao thứ hai của Hà Di Khánh và cũng là cơ sở để tạo điều kiện cho ông góp phần giữ vững vùng biên ải phía Bắc của Tổ quốc đó là ổn định về tình hình chính trị và phát triển kinh tế, nông nghiệp trong phạm vi châu Vị Long lúc bấy giờ.

Do tư liệu chính thống đề cập đến quá ít ỏi, nhất là những tư liệu ghi chép về lĩnh vực kinh tế của các vùng biên viễn nói chung và vùng châu Vị Long nói riêng dưới thời cai quản của Hà Di Khánh. Tuy vậy, thông qua những tư liệu được ghi lại trong văn bia Bảo Ninh Sùng Phúc, cho phép chúng ta phần nào phác họa được đôi nét về đời sống, kinh tế của châu Vị Long dưới thời kỳ cai quản của Thái phó Hà Di Khánh trong khoảng thời gian từ cuối thế kỷ XI, đầu thế kỷ XII.

Mở đầu văn bia đã giới thiệu về vùng châu Vị Long "tri Vị Long châu, phu ký lang, đô tri tả vũ vệ Đại tuớng quân, Kim tủ quang lộc đại phu, Kiểm hiệu Thái phó đồng Trung thu môn hạ bình chuoong sư, kiêm quản nội khuyến nông sự, Thuợng tru quốc, thực ấp tam thiên cửu bách hộ, thục thưc phong cưu bách hộ" [5, Tr. 109]. Dịch rằng "Tri

đường biờn giới dưới nước là 383.914 km (Theo Vũ Dương Ninh (2010), Đường biờn giới trờn đất liền giữa Việt Nam và Trung Quốc, Nxb Cụng an Nhõn dõn,H). 
châu Vị Long, Phò ký lang ${ }^{9}$ Đô tri tả vũ vệ Đại tuớng quân, Kim tử quang lộc đại phu, kiểm hiệu Thái phó, Đồng trung thu môn hạ Bình chuoong sụ, kiêm quản nội khuyến nông

Như vậy, qua văn bia cho chúng ta biết, ngoài việc được triều đình nhà Lý tin tưởng đặt nhiều chức quan, Hà Di Khánh còn được trao thêm chức Kiêm quản nội khuyến nông sư đó là chức quan trông coi công việc nông nghiệp tại Vị Long. Trong thời kỳ cai quản của mình, ông đã "cho dân cầy cấy theo phép Tỉnh điền ${ }^{10}$, thóc lúa ùn ùn như núi, khách khưa ba nghì đông đúc, cưa nhà nhộn nhịp phố phường" [5,Tr115]. Trong văn bia, tác giả Lý Thừa Ân cũng ca ngợi Thái phó Hà Di Khánh thu thuế của dân rất nhẹ nên đã đóng góp cho việc kích thích kinh tế nông nghiệp phát triển. Đời sống nhân dân ngày càng thịnh vượng. Cũng vì vậy mà Thái phó rất được lòng dân tại châu Vị Long.

Công lao thứ 3 của Thái phó Hà Di Khánh chính là góp phần truyền bá văn hóa Phật giáo vào vùng Vị Long nói riêng và vùng biên viễn phía Bắc của Tổ quốc nói chung.

Thời Lý, Phật giáo phát triển mạnh Triều Lý, các vị vua tôn sùng đạo Phật. Nhiều lần vua Lý cho người sang nhà Tống xin kinh Phật. Số lượng chùa tháp được xây dựng tương đối lớn cũng đủ để thấy đạo Phật đã thấm sâu và rộng thế nào trong dân chúng.

Sự tôn sùng đạo Phật của các vua nhà Lý cũng đã ảnh hưởng và có sức lan tỏa rất lớn đến tầng lớp quan lại và dân chúng. Phần lớn các chùa đều do vua, quan đứng lên xây dựng. Trong bối cảnh đó, Thái phó Hà Di Khánh cho xây dựng ngôi chùa Bảo Ninh Sùng Phúc ngay tại châu Vị Long. Ông xây dựng chùa vào năm 1107. "Hẳn là vị tri châu Thái phó Hà Di Khánh thấy cần phải xây dưng chùa tháp để nhờ các nhà su truyền dậy đạo Phật cho nguoòi dân trong bản châu mà ông cai quản" [6, tr21], vì ông biết rằng "Nước xây dựng trên đạo thì vũng nhu cột đá; Dân hấp thu giáo hóa thì xuôi nhu dòng sông" [6, tr115-116].

Vào thế kỷ XI, XII, triều đại nhà Lý chỉ quan tâm đến giáo dục ở khu vực kinh thành. Giáo dục ở các địa phương không được Nhà nước quan tâm. Vì vậy, các ngôi chùa của các làng ở nông thôn đồng bằng miền xuôi và những ngôi chùa ở vùng miền núi đóng vai trò như một trung tâm văn hóa, giáo dục. Nhiều nhà sư mở lớp dậy chữ cho các tăng nhi và dân chúng ngay tại các chùa.

\footnotetext{
${ }^{9}$ Phũ ký lang: Tức là chức Phũ mó sau này, dựng để pong cho con rể hoặc em rể vua.

${ }^{10} \boldsymbol{T} \boldsymbol{i} \boldsymbol{n} \boldsymbol{h}$ điền: phộp cầy ruộng và phộp đỏnh thuế của nhà Chu (Trung Quốc). Theo Đinh Khắc Thuõn trong Văn bia chựa Phật thời Lý: về cày ruộng thỡ đem 900 mẫu ruộng chia thành 9 khu, khu giữa là ruộng cụng,
}

sụ. Thuợng tru quốc, thưc ấp 3.900 hộ, hưởng thưc phong 900 hộ” [5, Tr113].

\section{Kết luận}

Thái phó Hà Di Khánh, có thể nói là một nhà chính trị có tâm, ông đã có cái nhìn rộng và chiến lược khi dựa vào các nhà sư, mở mang Phật học đến dân chúng trong vùng và dạy chữ cho dân. Ông đã góp phần ổn định về tình hình chính trị và phát triển kinh tế nông nghiệp trong phạm vi Châu Vị Long lúc bấy giờ. Vì thế, trong thời kỳ cai quản của Thái phó Hà Di Khánh, đời sồng nhân dân bình yên và no đủ.

Như vậy, có thể thấy rằng, Thái phó Hà Di Khánh có một sự nghiệp lớn lao, có công lao lớn đối với vùng châu Vị Long nói riêng và lịch sử dân tộc nói chung. Ông xứng đáng được tôn vinh là Danh nhân lịch sử của dân tộc Việt Nam nói chung và Tuyên Quang nói riêng.

\section{TÀI LIỆU THAM KHẢO}

1. Đào Duy Anh (1983), Đất nước Việt Nam qua các đời, Nhà xuất bản Khoa học Xã hội, Hà Nội.

2. Bảo tàng Tuyên Quang, Lý lịch di tích chùa Bảo Ninh Sùng Phúc thôn Làng Tạc, xã Yên Nguyên, Chiêm Hóa, tỉnh Tuyên Quang. Lần thứ nhất ngày 22 - 2- 1997 (Lí lịch di tích I) và lần 2 ngày 29 - 11- 2005 (Lí lịch di tích II).

3. Nguyễn Thị Phương Chi (2012), "Vai trò của những thủ lĩnh họ Hà đối với vùng đất Chiêm Hóa, Tuyên Quang", Hội thảo Hội thảo khoa học về các danh nhân ho Hà châu Vị Long, Tuyên Quang và giá trị tấm bia Bảo Ninh Sùng Phúc, tr. 61-70.

4. Ngô Sĩ Liêm (1981), Đại Việt sử ký toàn thu (tập 1), Nhà xuất bản Khoa học Xã hội, Hà Nội.

5. Thích Đức Thiện, Đinh Khắc Thuân (2011), Văn bia chùa Phật thời Lý, Nhà xuất bản Khoa học xã hội, Hà Nội.

6. Ủy ban nhân dân tỉnh Tuyên Quang (2012), Hội thảo khoa học về các danh nhân họ Hà châu Vị Long, Tuyên Quang và giá trị tấm bia Bảo Ninh Sùng Phúc. Kỷ yếu Hội thảo khoa học.

cũn khu ngoài để cho 8 nhà cày cấy, 8 nhà này phải chung sức cầy cấy khu ruộng ở giữa. Cũn về đỏnh phộp thuế thỡ cứ 100 mẫu thỡ phải nộp thuế 10 mẫu (thuế thập nhất). 


\title{
Contribution of Thai Pho Ha Di Khanh for national history from the 11th to 12th century
}

Hoang Thi Thu Dung,

Tran Minh Tu

Article info

\begin{abstract}
At persent, Bao Ninh Sung Phuc pagoda (Chiem Hoa district, Tuyen Quang province)

is preserving the only ancient stele which belongs to to the northern mountainous provinces with era from the Ly dynasty. The stele contents are about Ha clan and their contributions for Vi Long in particular and the country in general from the 11th to 12 th century, espeacially the great merit of historical hero Ha Di Khanh.
\end{abstract}

Recieved:

26/2/2020

Accepted:

10/6/2020

Keywords:

Contribution, $\mathrm{Ha} \mathrm{Di}$

Khanh, national history 
